\title{
New strategy for chemically attachment of Schiff base complexes on Multiwalled Carbon Nanotubes surfaces
}

\author{
Leila Moradi $^{\mathrm{a}^{*}}$, Maryam Rezaeei Bina ${ }^{\mathrm{b}}$ and Tayebe Partovi ${ }^{\mathrm{b}}$
}

${ }^{a}$ Faculty of Chemistry, Department of Organic Chemistry, University of Kashan, P.O. Box 87317-51167, I.R. Kashan, I. R. Iran ${ }^{b}$ Faculty of Science Department of Organic Chemistry, Payame Noor University of Tehran, 19395-3697, I.R. Iran

\section{H R O N I C L E}

Article history:

Received January 22, 2014

Received in revised form

February 02, 2014

Accepted 8 May 2014

Available online

22 May 2014

\section{Keywords:}

Multiwalled Carbon Nanotubes

Microwave irradiation

Functionalization of MWCNT

Schiff base

Salen complex@MWCNTs \begin{abstract}
A B S T R A C T
Chemically attachment of Schiff base complexes on multiwalled carbon nanotubes (MWCNTs) surfaces through a convenient and simple method was studied. In the first step of this method, we present a new method for preparation of aminated MWCNTs in order to attachment of (new) chlorinated salen Schiff bases. Amination of multiwalled carbon nanotubes performed under microwave (MW) irradiation through a one pot two step reaction. The chemically attachment of salen Schiff bases on functionalized MWCNTs (salen@MWCNTs) performed under a facile simple nucleophilic substitution reaction and complexation of attached salen Schiff bases (salen complex@MWCNTs) in last step, have been occurred with reaction of transition metal salts and salen@MWCNTs. The obtained products were characterized in detail, using FTIR, XRD, UV-Vis absorption, SEM and EDX methods.
\end{abstract}

C) 2014 Growing Science Ltd. All rights reserved.

\section{Introduction}

Until the 1980s, the carbon universe was built on the well-known modifications, graphite and diamond. This perspective totally changed with the discovery of the carbon allotropes such as fullerenes, carbon nanotubes ${ }^{1}$ (CNTs), carbon nanohorns, and carbon onions. Because of so many outstanding performances, CNTs exhibit great promise for potential applications in many technological fields such as hydrogen storage ${ }^{2-4}$, catalyst supports ${ }^{5,6}$, chemical sensors ${ }^{7,8}$ and nanoelectronic devices ${ }^{9}$. One of the most powerful approaches to improve CNT handling is the covalent functionalization of their side walls and tips ${ }^{10-13}$. A wide variety of reactions has been described for functionalization of CNTs. Because amine groups are versatile and undergo a variety of reactions, particular interest in functionalization processes is the attachment of amino groups (-NHR or $\mathrm{NH}_{2}$ groups) on CNT surfaces. In fact, the aminated MWCNTs have some advantageous for several applications, such as the attachment of nanoparticles to single and multiwalled carbon nanotubes ${ }^{14-16}$, the attachment of DNA to SWCNTs $^{17,18}$ and carbon nanofibers ${ }^{19,20}$ and also 
immobilization of Schiff base complexes ${ }^{21}$ on CNT surfaces. The Schiff bases and their metallic complexes have catalytic properties and can be used as homogen and heterogeneous catalysts in wide variety of chemical reactions ${ }^{22-26}$. The homogeneous catalysts, have some drawbacks such as difficulties in the catalyst recovery and product separation in contrast to heterogeneous catalysts, that have many advantages such as easy separation and facile recovery of the solid catalyst from the reaction mixture. In recent years, the interest of many researchers has been focused on heterogenizing of homogeneous catalysts, and there are a number of successful demonstrations of immobilized homogeneous complexes on supports. Heterogenization of homogeneous catalysts with similar activities affords an appealing methodology to expand the industrial application of homogeneous catalysts; for this purpose, immobilization of metal Schiff base complexes on organic or inorganic supports had been widely reported ${ }^{27-29}$. Immobilization via covalent bond on the support is more advantageous and improving the long-term stability of the solid catalyst.

Here we report a simple convenient method for chemically attachment of salen Schiff bases and Schiff base complexes to MWCNTs surfaces. In the first step of this method, we try to aminated of MWCNTs through a new one pot reaction and in second step, attachment of synthetic chlorinated Schiff bases (on CNT surfaces) performed under a nucleophilic substitution reaction. Complexation of attached salen Schiff base on MWCNTs (Salen complex@MWCNTs) has been occurred through the reaction of transition metal salts and salen@MWCNTs.

\section{Results and discussion}

The present method is containing to several steps: 1. amination of MWCNTs, 2. synthesis of chlorinated Schiff bases, 3. chemically attachment of Schiff bases to functionalized MWCNTs and 4. complexation of attached Schiff bases on MWCNTs.

The products of every step have been characterized with FTIR, UV-Vis absorption, XRD, SEM and EDX methods. In continue, we discuss about the obtained results.

\section{Conclusion}

Here we present a new method for chemically attachment of salen complexes to MWCNTS surfaces through a clean, convenient and fast method. Functionalization of MWCNTs with amino groups in first step, provide a useful material for attachment of chlromethylated salen Schiff bases via a nucleophilic substitution reaction. Analysis results show that CNTs were functionalized in a high concentration. After the immobilizing the Schiff bases to CNT surfaces, reaction of them with $\mathrm{Cu}$ and Ni salts, leads to Salen complex@MWCNTs.

Our method in functionalization of CNT surfaces has some advantages in compare with other reported results ${ }^{6,21}$, because of; here we don't use acids and hazardous reagents in procedure of the attachment of Schiff bases on CNT surfaces. Also aminated CNTs were prepared in fast and clean conditions. In fact, this new procedure provides functionalized CNTs (salen@MWCNTs and Salen complex@MWCNTs) with high concentration of functional groups. The final reaction products can be used as heterogeneous catalysts in chemical reactions. The process has proved to be very effective, safe and easy to operate and also the scale up of this method is easy.

\section{Aknowledgment}

We are grateful to the University of Kashan Research Council for the partial support of this work and thankful to the Department of Organic Chemistry, Payame Noor University of Tehran 


\section{Experimental}

\subsection{Materials}

Multiwalled carbon nanotubes were obtained from Shenzhen Nanotechnology Co., Ltd. (China) The Purity of the CNTs was about $90-95 \%$, with their diameters and lengths ranging between 20-40 $\mathrm{nm}$ and 5-15 $\mu \mathrm{m}$, respectively. The other reagents and solvents were purchased from Merck Company.

\subsection{Apparatus}

FT-IR spectra were recorded on a Bruker ISS-88 spectrophotometer in KBr pellets. ${ }^{1} \mathrm{H}$ NMR (400 $\mathrm{MHz}$ ) spectra were measured in $\mathrm{CDCl}_{3}$ solvent and referenced to the solvent signals by Bruker Avance DPX instrument. The spectra in the UV-Vis range were taken using Cary 100 varian el 12092335 UV-Vis scanning spectrometer. ASTRA 3D Bath sonicator was applied for debundeling of MWCNTs also XRD instrument model Philips Analytical PC-APD was used for characterization of the reaction products. Cambridge 360 scanning electron microscope (SEM) with energy dispersive Xray spectroscopy (EDX) analysis was used for surface image measurements and chemical characterization of $\mathrm{Cu}$ and Ni salencomplex@MWCNTs.

\subsection{General procedure for amination of MWCNTs}

$180 \mathrm{mg}$ of $\mathrm{AlCl}_{3}$ mixed with $10 \mathrm{mg}$ MWCNTs and grind for 5 minutes and then added to $50 \mathrm{ml}$ $\mathrm{CH}_{2} \mathrm{Cl}_{2}$. The mixture was sonicated for 10 minutes in bath sonicator. After that, the homogen mixture was irradiated in a microwave oven for 10 minutes with power of 900 watt. After this time, $200 \mathrm{mg}$ of ammonium benzoate (as ammonia source) was added to the mixture and the reaction continues for 10 minutes under microwave irradiation with power of 900 watt. After this time, the mixture cool to room temperature and filtered. Then $50 \mathrm{ml}$ warm ethanol were added and sonicated for $10 \mathrm{~min}$ to remove remained unreacted compounds, and then the mixture was filtered and the resulting products were dried at $80^{\circ} \mathrm{C}$ for 10 hours (Scheme 1).

\subsection{Chloromethylation of Salicylaldehyde}

$17.5 \mathrm{~g} \mathrm{(160} \mathrm{mmol)} \mathrm{salicylaldehyde,} 24 \mathrm{ml}$ formaldehyde, $1.2 \mathrm{~g} \mathrm{ZnCl}_{2}$ and $100 \mathrm{ml}$ of concentrate $\mathrm{HCl}$ were poured in a $250 \mathrm{ml}$ flask and stirred for 24 hours at room temperature (under $\mathrm{N}_{2}$ atmosphere). After this time, a white solid was formed .To isolate the product, [5-chloro-methyl-2hydroxy-Benzaldehyde (1)], the solids dissolved in diethyl ether, and the organic phase was washed by saturated sodium bicarbonate. For removal of water from organic phase, a small amount of magnesium sulfate was added and crystallization was performed in petroleum ether ${ }^{30}$ (Scheme 2).

\subsection{General procedure for synthesis of Schiff Bases}

$3.41 \mathrm{~g} \mathrm{(20} \mathrm{mmol)} \mathrm{of} \mathrm{5-chloro-methyl-2-hydroxy-Benzaldehyde} \mathrm{(1)} \mathrm{was} \mathrm{dissolved} \mathrm{in} \mathrm{a} \mathrm{minimum} \mathrm{of}$ dichloromethane. Then, according to the stoichiometry of 1 to 2 of diamine to $\mathbf{1}$, the amounts of diamines was mesured and dissolved in minimum volume of dichloromethane and were added to 1. The mixture was stirred in room temperature for 1 to 3 hours (the completion of reaction monitored by TLC). After this time, the solution was filtered and the obtained precipitate was washed with dichloromethane and dried in $70^{\circ} \mathrm{C}$ for 6 hours (Scheme 2).

\subsection{General procedure for synthesis of salen @MWCNTs}

$50 \mathrm{mg}$ of aminated MWCNTs were added to $8 \mathrm{ml}$ of methanol containing $100 \mathrm{mg}$ of Schiff base and refluxed for 24 hours at $70^{\circ} \mathrm{C}$. After this time, the reaction mixture was filtered and washed with methanol and finally was dried at $70^{\circ} \mathrm{C}$ in oven (Scheme 3 ). 
$0.5 \mathrm{~g}$ of transition metal salts were dissolved in $20 \mathrm{ml}$ of methanol and $1 \mathrm{~g}$ of salen @MWCNTs (from previous step), was added and refluxed in $40^{\circ} \mathrm{C}$ for about 4 hours. After that, the mixture was cooled to room temperature and filtered and finally, the reaction product washed with $\mathrm{MeOH}$ and dried (Scheme 4).

\subsection{Characterization of aminated MWCNTs}

\subsubsection{FTIR}

The high symmetry presented on raw CNTs generates very weak infrared signals due to the weak difference of charge state between carbon atoms. The weak difference of charge state leads to very small induced electric dipole, providing a silent spectrum. In FTIR spectrum of raw and aminated MWCNTs (Fig. 1), several peaks are exist.
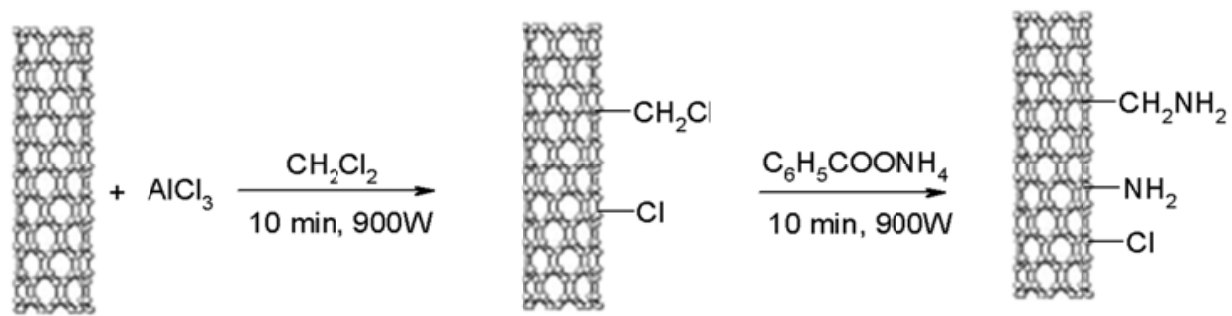

Scheme 1. The procedure used for functionalization of MWCNTs

The peak related to $\mathrm{C}=\mathrm{C}$ bond at approximately $1600 \mathrm{~cm}^{-1}$ is not seen clearly in the spectrum of pristine CNTs. This effect can be explained by the very low formation of electric dipoles. The functionalization breaks the symmetry of nanotubes structures, which enhances the generation of induced electric dipoles and signs as detected. Peaks at 3500 and about $2900 \mathrm{~cm}^{-1}$ (Fig. 1) are the characteristic stretching vibrations of $\mathrm{N}-\mathrm{H}$ and $\mathrm{C}-\mathrm{H}$ bonds. Aminated CNTs, also show the appearance of a peak approximately at $1050 \mathrm{~cm}^{-1}$, which corresponds to the $\mathrm{C}-\mathrm{N}$ stretching indicating the attachment of $\mathrm{NH}_{2}$ groups due to surface modification.
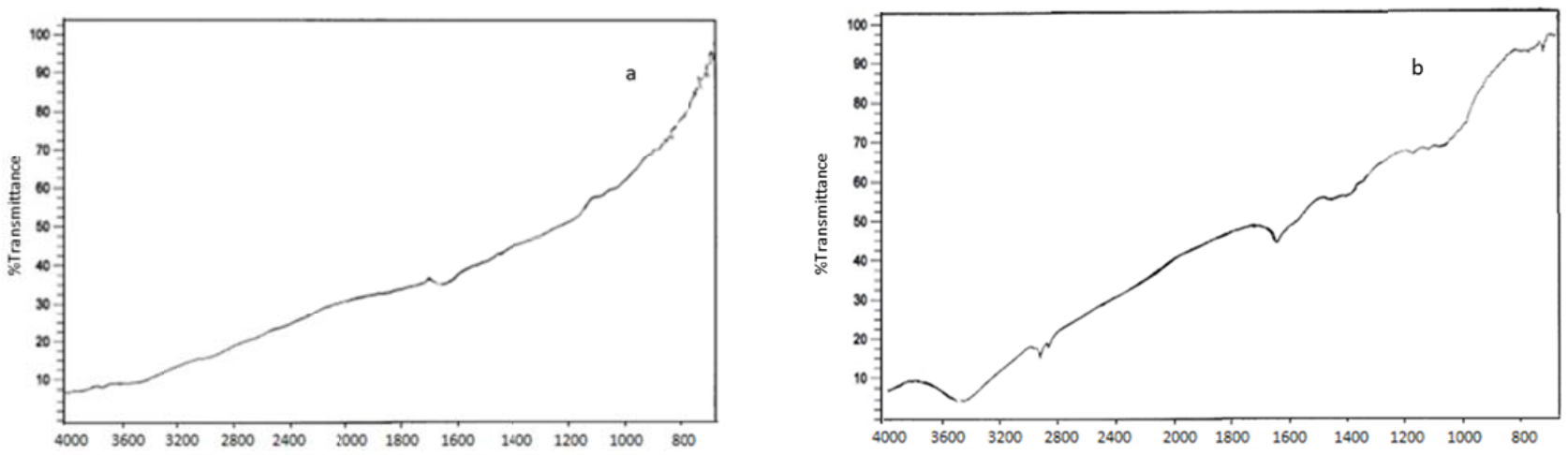

Fig. 1. FTIR spectra of raw (a) and aminated (b) of MWCNTs

\subsection{2. $X R D$}

Fig. 2 exhibits the XRD patterns of pristine and modified MWCNTs. XRD patterns show that MWCNTs have similar cylinder wall structures before and after the modification. In addition, interplanner spacing of functionalized materials remained the same. These results demonstrate that the functionalization would not change the structure of MWCNTs. 

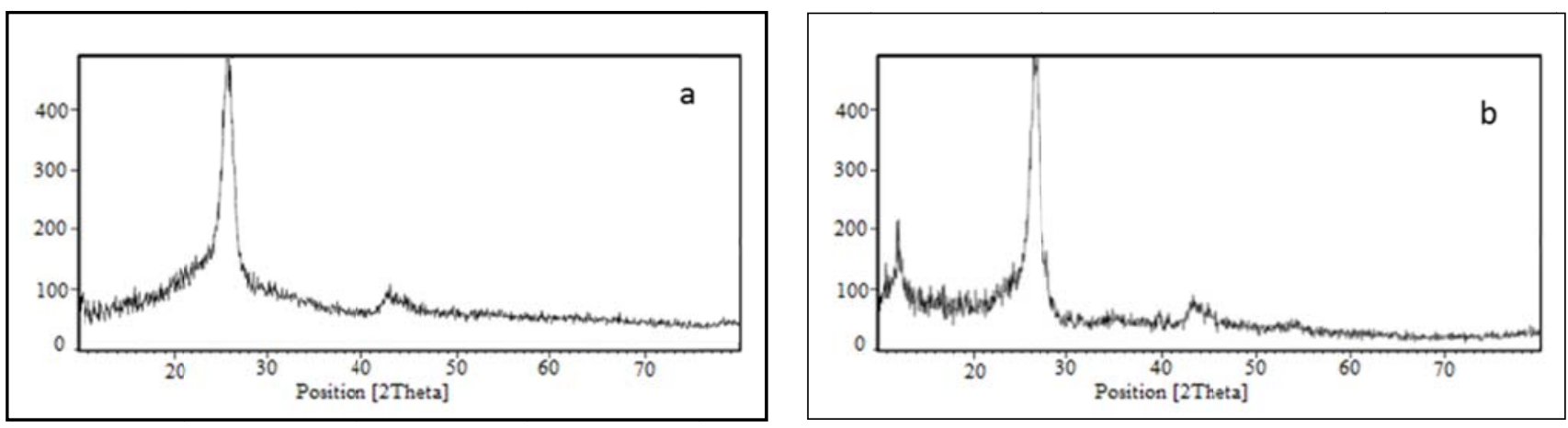

Fig. 2. XRD patterns of Raw (a) and Functionalized MWCNTs (b)

\subsubsection{Settling behavior}

To estimate the dispersibility of raw and modified MWCNTs, a sedimentation test was performed. Aminated MWCNTs (1mg) were ultrasonically dispersed in ethanol for $5 \mathrm{~min}$. It was observed that aminated MWCNTs could be easily dispersed in ethanol due to hydrogen bondls, that could be formed between aminated MWCNTs and polar solvent molecules. Modified MWCNTs could be dispersed when hydrogen bonds overcome the van der waals interactions among MWCNTs. Fig 3. shows the stability of dispersion after 3 weeks.

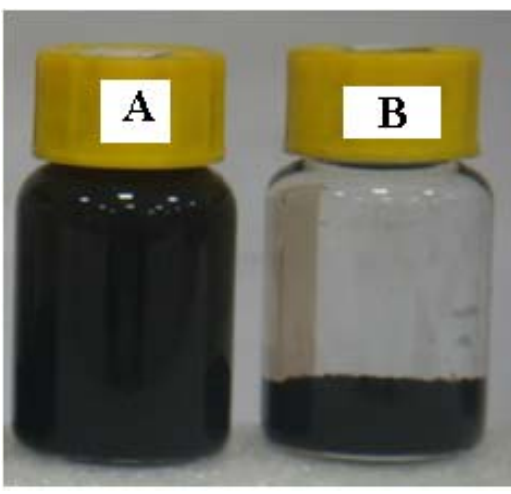

Fig. 3. Photographs of dispersion stability of: functionalized (A) and raw MWCNTs (B)

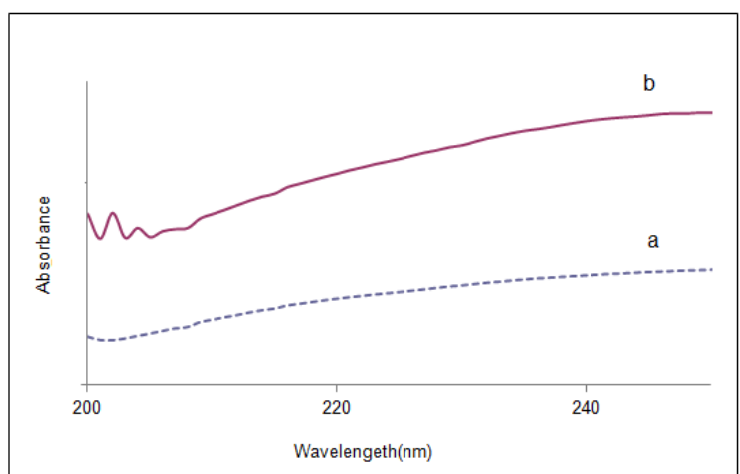

Fig. 4. UV-Vis absorbtion spectra of raw (a) and aminated MWCNTs (b)

\subsubsection{UV-Vis absorption}

UV-visible absorption spectrum can also verify the functionalization of carbon nanotubes. UV-Vis absorption spectra of raw and aminated nanotubes (in ethanol) have been shown in Fig. 4. Pristine MWCNTs (dispersed in ethanol) do not show any optical absorption at room temperature. However, after functionalization with $-\mathrm{NH}_{2}$ groups, optical absorption peak below $210 \mathrm{~nm}$ is observed. These bands are due to $n \rightarrow \sigma^{*}$ transition electrons of amino groups.

\subsection{Characterization of synthetic Schiff bases}

For synthesis of chlorinated Schiff bases, 5-chloromethyl-2-hydroxy benzaldehyde (1)were prepared from salycil aldehyde, through an electerophilic substitution reaction (Scheme 2). The reaction product was characterized by FTIR and ${ }^{1} \mathrm{H}$ NMR techniques.

IR $\left(\mathrm{KBr}, \quad \mathrm{cm}^{-1}\right), 3200(-\mathrm{OH}), 2900\left(-\mathrm{CH}_{2}\right), 1650(\mathrm{C}=\mathrm{O}), 1490-1500$ (aromatic $\left.\mathrm{C}=\mathrm{C}\right), 1260\left(-\mathrm{CH}_{2}\right)$, 720 (C-Cl).

${ }^{1} \mathrm{H}$ NMR $\left(\mathrm{CDCl}_{3}, \delta \mathrm{ppm}\right), 11.08(\mathrm{~s}, 1 \mathrm{H}), 9.91(\mathrm{~s}, 1 \mathrm{H}), 7.0-7.6(\mathrm{~m}, 3 \mathrm{H}), 4.6(\mathrm{~s}, 2 \mathrm{H})$. 
Chlorinated Schiff Bases, [N,Ń-bis (3-chloro methyl salysilidine) 1,4-butanediamine (salen 2) and N,Ń-bis (3-chloro methyl salysilidine) 1,8-octanediamine (salen 3)], were synthesized by the reaction of diamines (1,4- diamino butane and 1,8 diamino octane) with $\mathbf{1}$, respectively (scheme 2).
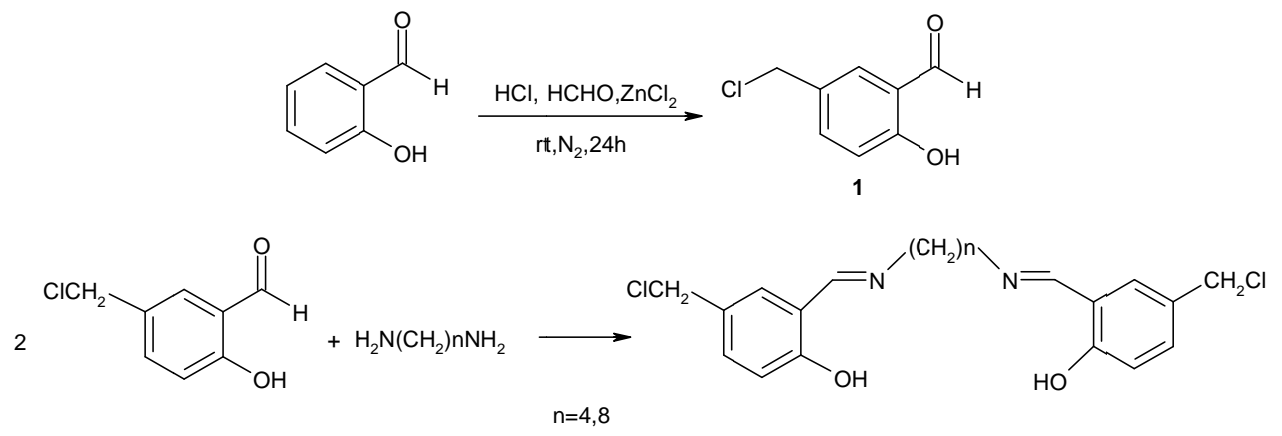

Scheme 2. The procedure of preparation of chlorinated salen Schiff bases

\subsubsection{FTIR}

The structure of the chlorinated Schiff bases were confirmed by the presence of several bands in their FTIR spectra. A broad absorption band is related to $\mathrm{O}-\mathrm{H}$ stretching vibrations in the region $3300-3600 \mathrm{~cm}^{-1}$, aromatic C-H stretching vibration in $300-3100 \mathrm{~cm}^{-1}$, aliphatic $\mathrm{C}-\mathrm{H}$ vibration at 2850 and $2960 \mathrm{~cm}^{-1}$, strong $\mathrm{C}=\mathrm{N}$ and $\mathrm{C}=\mathrm{C}$ absorption bands respectively at 1620 and $1500-1520 \mathrm{~cm}^{-1}$ and $\mathrm{C}-\mathrm{Cl}$ band at about $750 \mathrm{~cm}^{-1}$ confirm the structure of the products (Fig. 5).

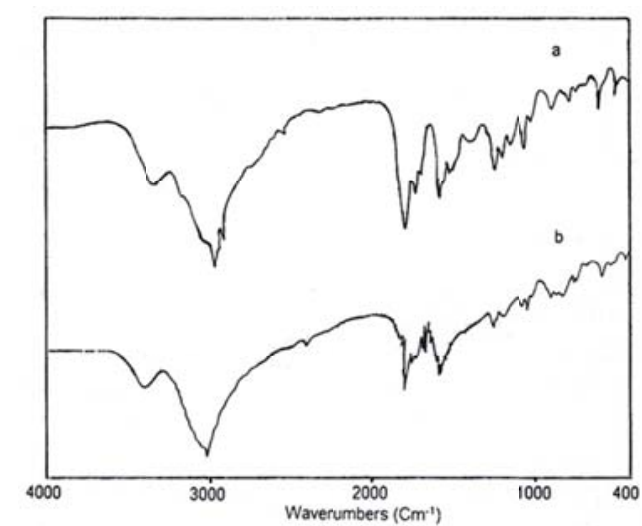

Fig. 5. FTIR spectra of salen 2 (a) and 3(b)

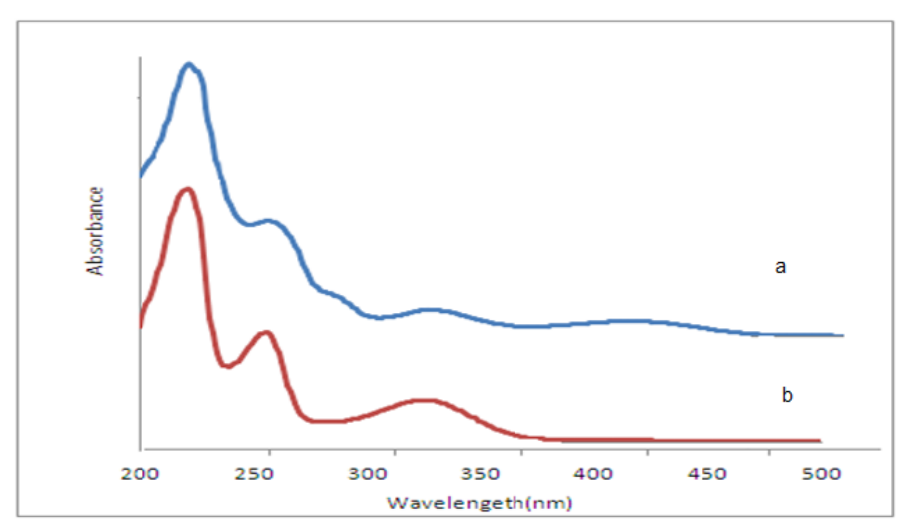

Fig. 6. UV-Vis spectra of salen 2 (a) and 3 (b)

\subsubsection{UV-Vis absorption}

In UV-Vis absorption spectra of Schiff bases (Fig. 6), the compounds exhibit intense bands in the 200-400 nm regions. These absorption bands may be assigned to $n \rightarrow \pi^{*}$ and $\pi \rightarrow \pi^{*}$ transitions. The $210-300 \mathrm{~nm}$ bands are due to the $\pi \rightarrow \pi^{*}$ transitions of the aromatic rings and the bands at the 300$350 \mathrm{~nm}$ range, involve $\pi \rightarrow \pi^{*}$ transitions of the $\mathrm{C}=\mathrm{N}$ group in salen Schiff base 2 and 3 .

\subsection{Characterization of salen @MWCNTs}

\subsubsection{FTIR}

Salen Schiff bases were chemically attached to aminated MWCNTs through a simple nucleophilic substituted reaction (Scheme 3). The reactions products were characterized by FTIR, UV-Vis and SEM techniques. 


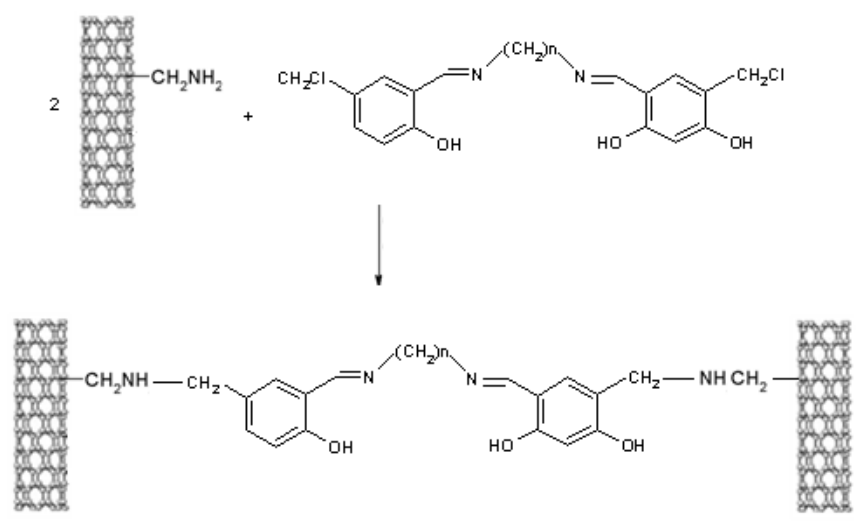

Scheme 3. Procedure of preparation of salen@MWCNTs

The FTIR spectra of functionalized MWCNTs are shown in Figs. 7. The IR spectra of functionalized MWCNTs contain several bands due to Schiff base structures. A broad band at about $3450 \mathrm{~cm}^{-1}$ is related to the bending mode of O-H groups. Peaks at about 2800 and $2920 \mathrm{~cm}^{-1}$ are due to $\mathrm{C}-\mathrm{H}$ stretching modes of the $\mathrm{CH}_{2}$ groups. The stretching band of the $\mathrm{C}=\mathrm{N}$ groups appears at around $1600 \mathrm{~cm}^{-1} . \mathrm{C}=\mathrm{C}$ and $\mathrm{C}-\mathrm{N}$ vibrations appear in $1420-1550$ and $1050 \mathrm{~cm}^{-1}$ respectively. These results indicate that salen Schiff bases attachment to the MWCNTs surfaces performed successfully.
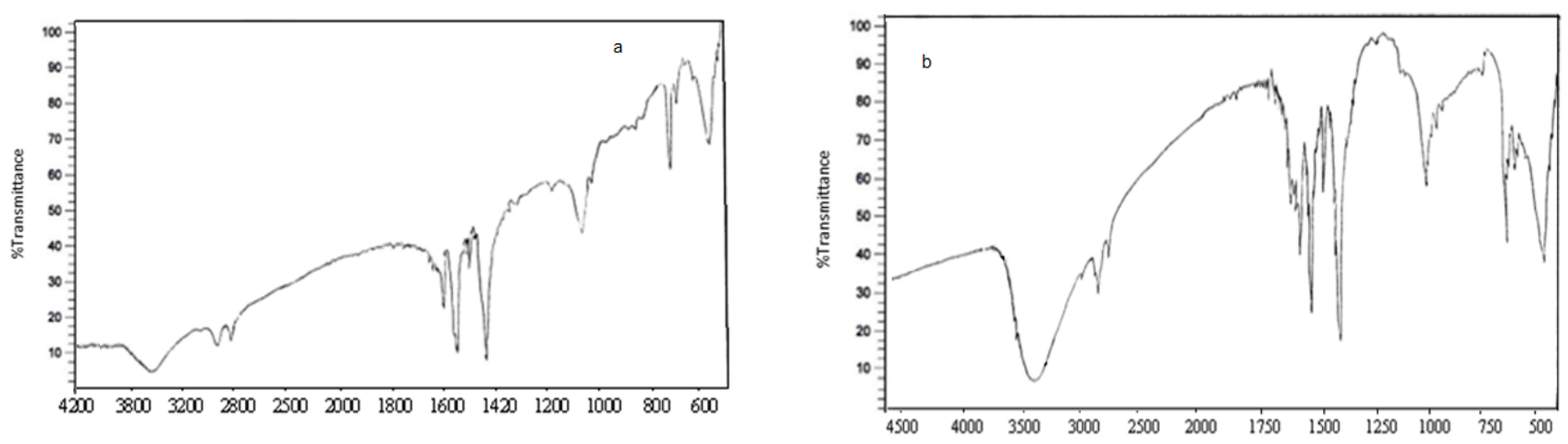

Fig. 7. FTIR spectra of salen 2@MWCNTs (a), Salen3@MWCNTs (b)

\subsubsection{UV-Vis absorption}

From comparison of adsorption spectra of salen Schiff bases (Fig. 6) and salen@MWCNTs (Fig.8), it clearly can be recognized, that the Schiff bases were chemically attached to the surfaces of functionalized CNTs.

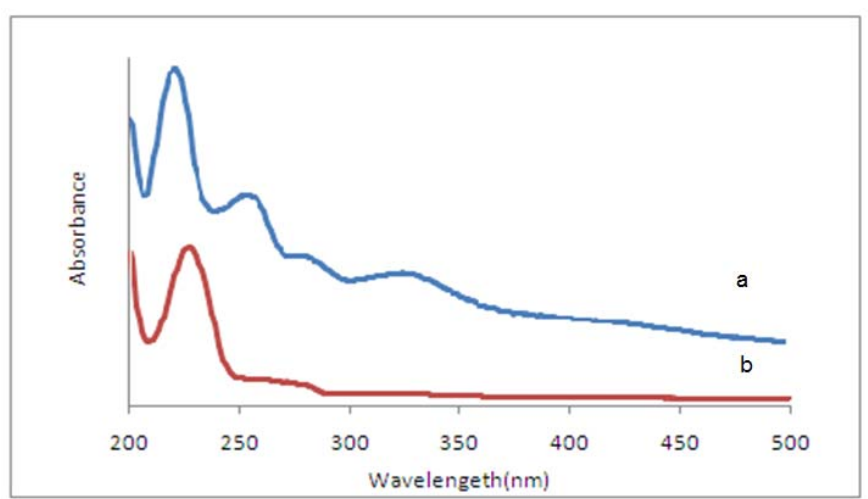

Fig. 8. Uv-Vis spectra of salen 2@MWCNTs (a) and salen 3@MWCNTs (b) 


\subsubsection{SEM}

Fig. 9 exhibits a comparison of the SEM images of raw and salen@MWCNTs. importantly, the MWCNTs have found to be remained to their length. In fact, cutting of nanotubes has not occurred during the reaction procedure. These images also reveal that the nanotube diameters become thicker after functionalization and also the endcaps of CNTs were opened.
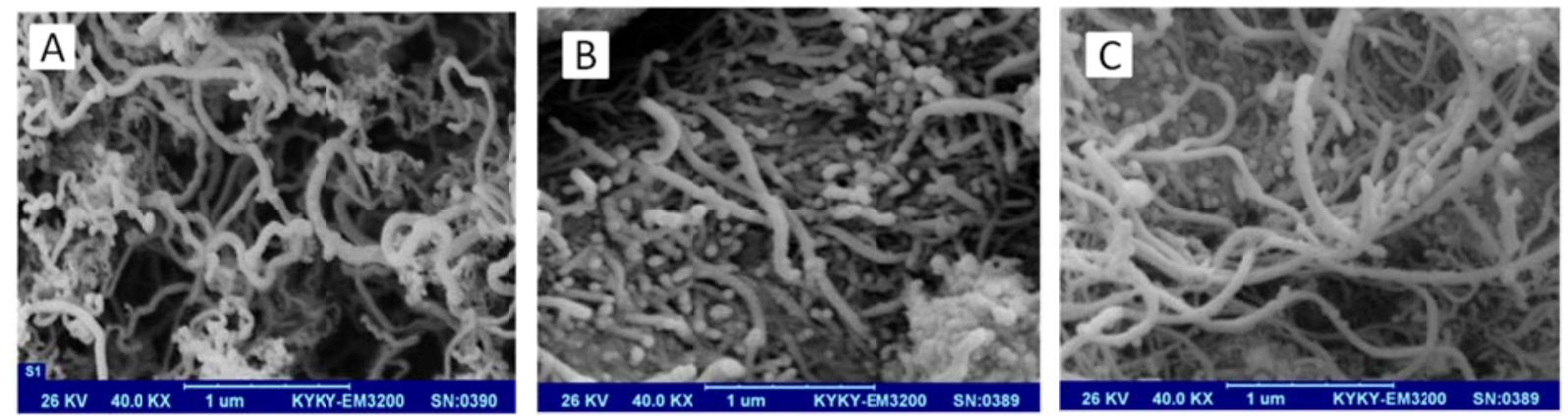

Fig. 9. SEM images of raw MWCNTs (A), salen2@MWCNTs (B) and salen3@MWCNTs (C)

\subsection{Characterization of salen complex@MWCNTs}

Conversion of Schiff base @MWCNTs to their complex moieties can be occurred through the reaction of transition metal salts with Schiff base @MWCNTs (Scheme 4). Here we prepare Cu and Ni complexes@MWCNTs.
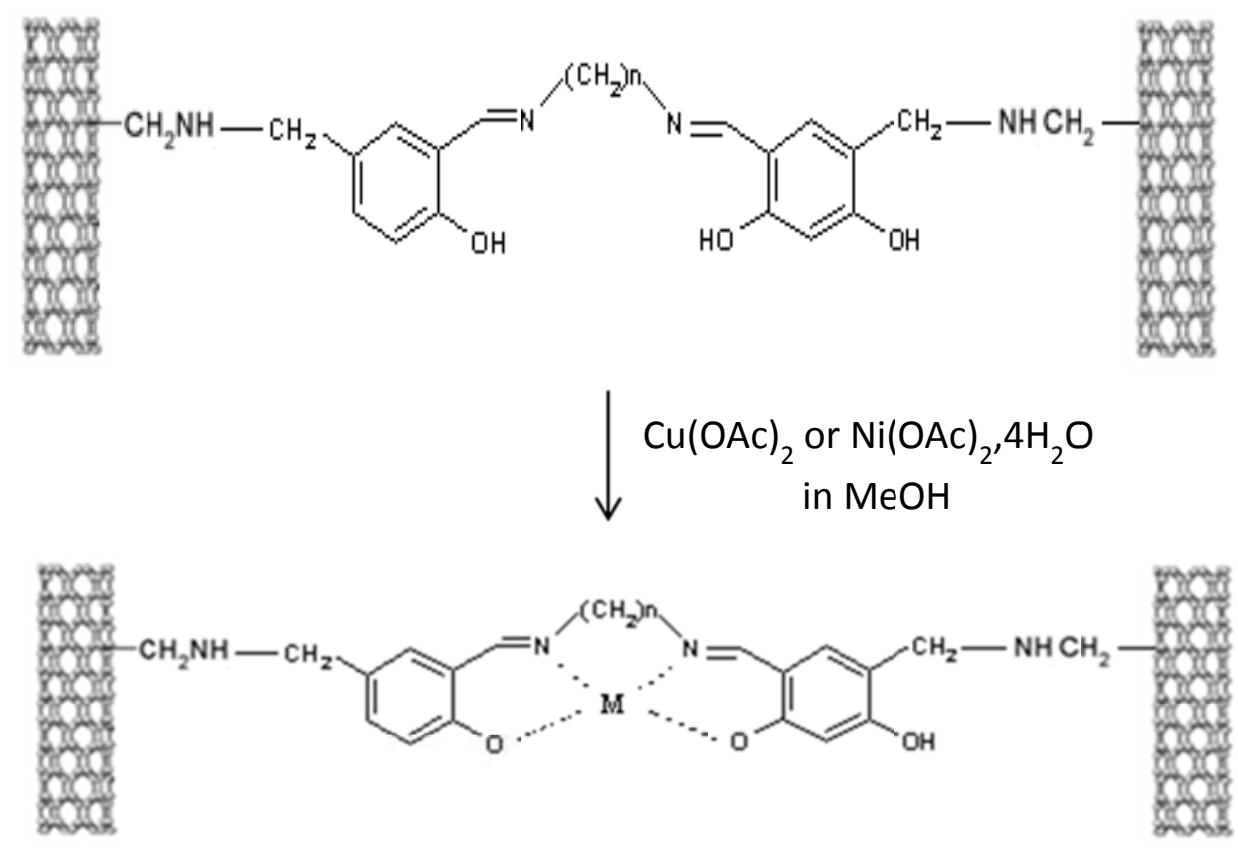

$\mathrm{M}=\mathrm{Cu}$ or $\mathrm{Ni}$

Scheme 4. Preparation of salen complex@MWCNTs

\subsubsection{XRD}

The attachment of salen complexes on MWCNTs can be supported by XRD analysis. Fig. 10 shows XRD patterns of salen complexes@ MWCNTs. Pristine MWCNTs, has peaks at $25.95^{\circ}$ and $43.38^{\circ}$ (Fig. 2). The patterns of $\mathrm{Cu}$ and Ni complexes@MWCNTs differ from those of raw MWCNTs due to transition metal chelation to salen@MWCNTs. According to the FTIR and UV-Vis results, it is believed that metal supported catalyst on MWCNTs is indeed obtained. 

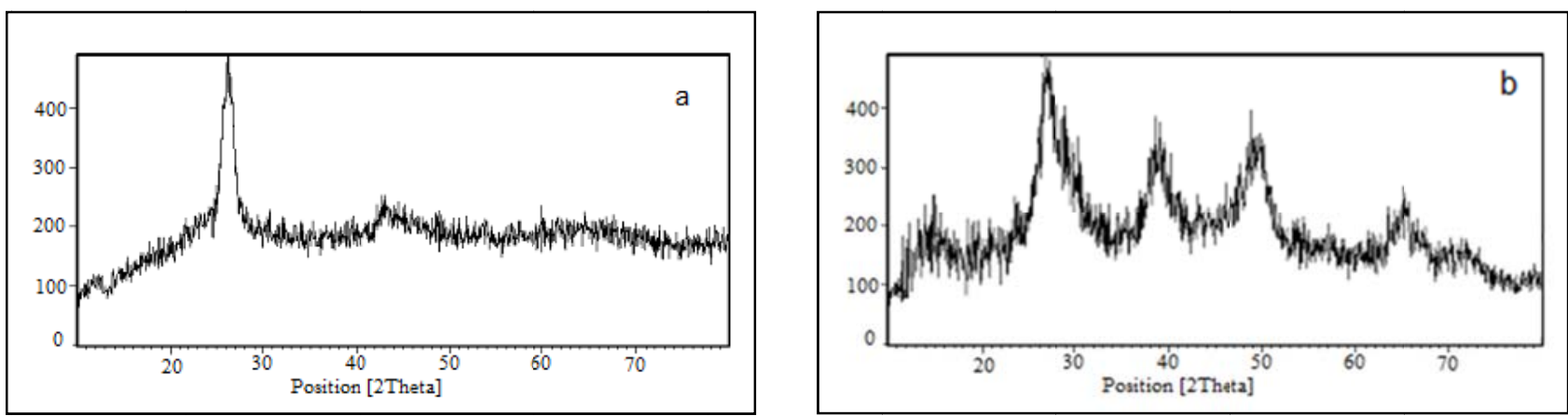

Fig.10. XRD patterns of: (a) Cu complex@MWCNTs and (b) Ni Complex@MWCNTs (from 2@MWCNTs)

\subsubsection{EDX analysis}

Fig. 11 give the EDX distribution of elements for the $\mathrm{Cu}$ and Ni complexe@MWCNTs. The existence of $\mathrm{C}, \mathrm{O}, \mathrm{Cu}$ and $\mathrm{Ni}$ in the functionalized $\mathrm{CNTs}$ was confirmed by the XRD results and show that the metal complexes were successfully attached on the CNT surfaces.
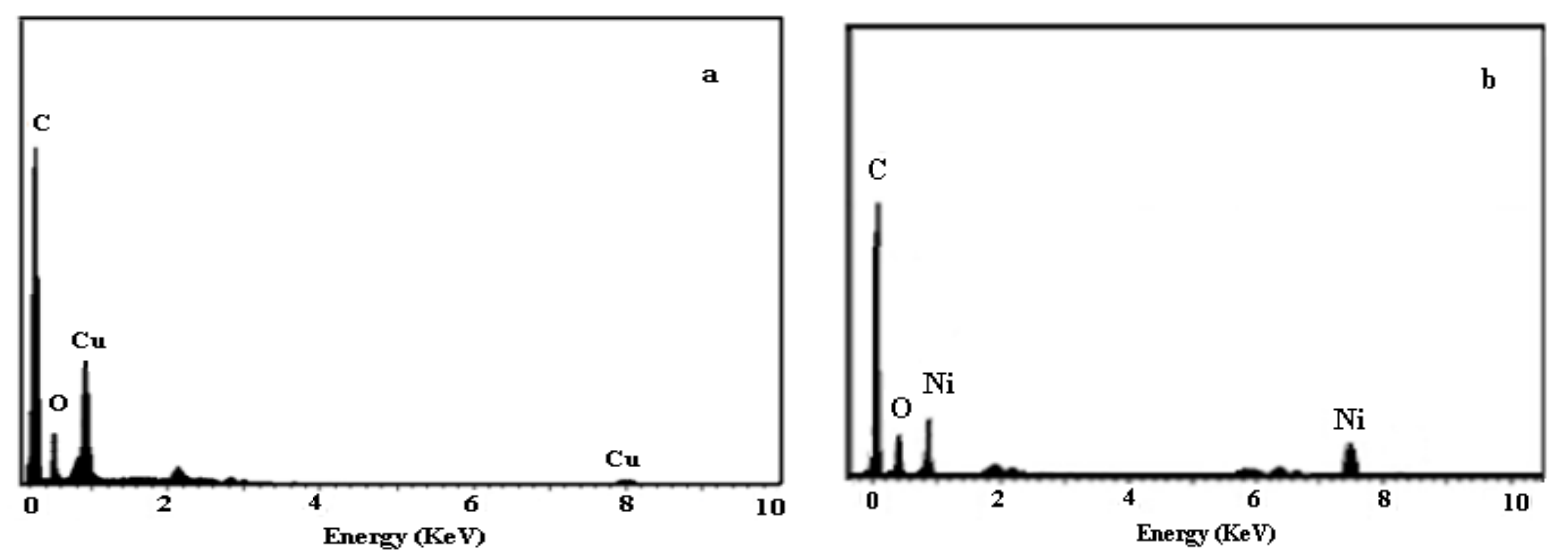

Fig.11. EDX of Cu (a) and Ni (b) complex@MWCNT

\section{References}

1 Iijima S. (1991) Helical microtubules of graphitic carbon. Nature., 354, 56-58.

2 Lee S.M., Lee Y.H. (2000) Hydrogen storage in single-walled carbon nanotubes. Appl. Phys. Lett., 76, 2877-2879.

3 Rahimi N., Sabbaghi S., Sheikhi M. H. (2012) Hydrogen storage in carbon nanotubes with Ni nanoparticles by electrochemical., Int. J. Nano., 2, 165-169.

4 Bhowmick R., Rajasekaran S., Friebel D., Beasley C., Jiao L.Y., Ogasawara H., Dai H.J., Clemens B., Nilsson A. (2011) Hydrogen Spillover in Pt-Single-Walled Carbon Nanotube Composites: Formation of Stable C-H Bonds. J. Am. Chem. Soc., 133 5580-5586.

5 Grivani G., Tangestaninejad S., Halili A. (2007) A readily prepared, highly reusable and active polymer-supported molybdenum carbonyl Schiff base complex as epoxidation catalyst. Inorg. Chem. Commun., 10, 914-917.

6 Salavati-Niasari M., Esmaeili E., Seyghalkar H., Bazarganipour M. (2011) Cobalt (II) Schiff base complex on multi-wall carbon nanotubes (MWNTs) by covalently grafted method: Synthesis, characterization and liquid phase epoxidation of cyclohexene by air. Inorg. Chim. Acta., 375, 11-19.

7 Collins P.G., Bradley K., Ishigami M., Zettl A. (2000) Extreme oxygen sensitivity of electronic properties of carbon nanotubes. Science., 287, 1801-1804.

8 Chen G., Paronyan T. M., Pigos E. M., Harutyunyan A. R., (2012) Enhancedl gas sensing in pristine carbon nanotubes under continuous ultraviolet light illumination. Sci. Rep., 2, 343-347.

9 Cress C. D., McMorrow J. J., Robinson J. T., Landi B. J., Hubbard S. M., Messenger S. R., (2012) Radiation Effects in Carbon Nanoelectronics. Electronics., 1, 23-31. 
10 Tasis D., Tagmatarchis N., Bianco A., and Prato M. (2006) Chemistry of carbon nanotube. Chem. ReV., 106, 1105-1138.

11 Pan B., Cui D., He R., Gao F., Zhang Y. (2006) Covalent attachment of quantum dot on carbon nanotubes. Chem. Phys. Lett., 417, 419-424.

12 Wang Y., Iqbal Z., Malhotra S. (2005) Functionalization of carbon nanotubes with amines and enzymes. Chem. Phys. Lett., 402, 96-101.

13 Su X., Shuai Y., Guo Z., Feng Y. (2013) Functionalization of Multi-Walled Carbon Nanotubes with Thermo-Responsive Azide Terminated Poly( $N$-isopropylacrylamide) via Click Reactions Molecules., $18,4599-4612$.

14 Georgakilas V., Gournis D., Tzitzios V., Pasquato L., Guldi D.M., Prato M. (2007) decorating carbon nanotubes with metal semiconductor nanoparticles. J. Mater. Chem., 17, 2679-2694.

15 Haremza J. M., Hahn M. A., Krauss T. D., Chen S., Calcines J. (2002) Attachment of Single CdSe Nanocrystals to Individual Single-Walled Carbon Nanotubes. Nano Lett., 2, 1253-1258.

16 Kumar S., Kaur I., Dharamvir K., Bharadwaj L. M. (2012) Controlling the density and site of attachment of gold nanoparticles onto the surface of carbon nanotubes, J. Colloid. Interface. Sci., 369, 23-27.

17 Baker S.E., Cai W., Lasseter T.L., Weidkamp K.P., Hamers R.J. (2002) covalently bonded adducts of deoxyribonucleic acid (DNA) oligonuclotides with single wal carbon nanotubes:synthesis and hybridization. Nano Lett., 2, 1413-1417.

18 Awasthi K., Singh D. P., Singh S., Dash D., Srivastava N. O. (2009) Attachment of biomolecules (protein and DNA) t0 amino-functionalized carbon nanotubes., New Carbon Mater., 24, 301-306.

19 Baker SE., Tse KY., Hindin E., Nichols BM., Clare TL., Hamers RJ. (2005) Covalent functionalization for biomolecular recognition on vertically aligned carbon nanofibers. Chem. Mater., 17, 4971-4978.

20 Wipawakarn P., Ju H., Wong D. K. Y. (2012) label-free electrochemical DNA biosensor based on a $\mathrm{Zr}(\mathrm{IV})$-coordinated DNA duplex immobilised on a carbon nanofibre/chitosan layer. Anal. Bioanal Chem. A., 402, 2817-2826.

21 Salavati-Niasari M., Bazarganipour M. (2008) Covalent functionalization of multi-wall carbon nanotubes (MWNTs) by nickel(II) Schiff-base complex: Synthesis, characterization and liquid phase oxidation of phenol with hydrogen peroxide. Appl. Surf. Sci., 255, 2963-2970.

22 Bhunia S., Koner S. (2011) Tethering of nickel(II) Schiff-base complex onto mesoporous silica: An efficient heterogeneous catalyst for epoxidation of olefins. Polyhedron, 30, 1857-1864.

23 Rayati S., Zakavi S., Koliaei M., Wojtczak A., Kozakiewicz A. (2010) Electron-rich salen-type Schiff base complexes of $\mathrm{Cu}(\mathrm{II})$ as catalysts for oxidation of cyclooctene and styrene with tertbutylhydroperoxide: A comparison with electron-deficient ones. Inorg. Chem. Commun., 13, 203-207

24 Rayati S., Koliaei M., Ashouri F., Mohebbi S., Wojtczak A., Kozakiewicz A. (2008) Oxovanadium(IV) Schiff base complexes derived from 2,20-dimethylpropandiamine: A homogeneous catalyst for cyclooctene and styrene oxidation. Appl. Catal. A: General., 346, 65-71.

25 Naeimi H., Karshenas A. (2013) Highly regioselective conversion of epoxides to $\beta$-hydroxy nitriles using metal(II) Schiff base complexes as new catalysts under mild conditions. Polyhedron 49, 234 238.

26 Ding L., Jin W., Chu Z., Chen L., Lü X., Yuan G., Song J., Fan D., Bao F. (2011) Bulk solvent-free melt ring-opening polymerization (ROP) of L-lactide catalyzed by $\mathrm{Ni}(\mathrm{II})$ and $\mathrm{Ni}(\mathrm{II})-\mathrm{Ln}(\mathrm{III})$ complexes based on the acyclic Salen-type Schiff-base ligand. Inorg. Chem. Commun., 14, 1274-1278.

27 Ayala V., Corma A., Iglesias M., Rincon J.A., Sanchez F. (2004) Hybrid organic-inorganic catalysts: a cooperative effect between support, and palladium and nickel salen complexes on catalytic hydrogenation of imines. J. Catal., 224, 170-177.

28 Holbach M., Weck M. (2006) Modular Approach for the Development of Supported, Mono Functionalized Salen Catalysts. J. Org. Chem., 71, 1825-1836.

29 Bhunia S., Koner S. (2011) Tethering of nickel(II) Schiff-base complex onto mesoporous silica: An efficient heterogeneous catalyst for epoxidation of olefins. Polyhedron 30, 1857-1864

30 Yang Y., Zhang Y., Hao S., Guan J., Ding H., Shang F., Qiu P., Kan Q. (2010) Heterogenization of functionalized $\mathrm{Cu}(\mathrm{II})$ and $\mathrm{VO}(\mathrm{IV})$ Schiff base complexes by direct immobilization onto aminomodified SBA-15: Styrene oxidation catalysts with enhanced reactivity. Appl. Catal. A: General., 381, $274-281$. 